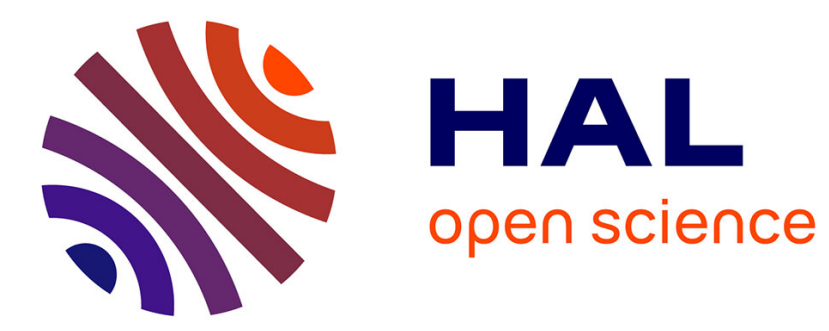

\title{
Feeding behaviour of red fox and domestic cat populations in suburban areas in 1 the south of Paris 2
}

Irene Castañeda, Diane Zarzoso-Lacoste, Elsa Bonnaud

\section{To cite this version:}

Irene Castañeda, Diane Zarzoso-Lacoste, Elsa Bonnaud. Feeding behaviour of red fox and domestic cat populations in suburban areas in 1 the south of Paris 2. Urban Ecosystems, 2020, 23 (4), pp.731-743. $10.1007 / \mathrm{s} 11252-020-00948-\mathrm{w}$. hal-02985985

\section{HAL Id: hal-02985985 \\ https://hal.sorbonne-universite.fr/hal-02985985}

Submitted on 2 Nov 2020

HAL is a multi-disciplinary open access archive for the deposit and dissemination of scientific research documents, whether they are published or not. The documents may come from teaching and research institutions in France or abroad, or from public or private research centers.
L'archive ouverte pluridisciplinaire HAL, est destinée au dépôt et à la diffusion de documents scientifiques de niveau recherche, publiés ou non, émanant des établissements d'enseignement et de recherche français ou étrangers, des laboratoires publics ou privés. 
1 Feeding behaviour of red fox and domestic cat populations in suburban areas in

2 the south of Paris

3 Irene Castañeda ${ }^{1,2}$, Diane Zarzoso-Lacoste ${ }^{2,3}$, Elsa Bonnaud ${ }^{2}$

$4 \quad{ }^{1}$ Centre d'Ecologie et des Sciences de la Conservation (CESCO UMR 7204), Sorbonne

5 Universités, MNHN, CNRS, UPMC, 43 rue Buffon, CP51, 75005, Paris, France.

$6 \quad{ }^{2}$ Ecologie Systématique Evolution, Univ. Paris-Sud, CNRS, AgroParisTech, Université

7 Paris-Saclay, 91400, Orsay, France

8 3'Unité "Ecologie et Dynamique des Systèmes Anthropisés" (UMR7058 CNRS),

9 Université de Picardie Jules Verne, 1 rue des Louvels, 80037 Amiens Cedex 1, France

10

11 Corresponding author:

12 Irene Castañeda

13 Ecologie, Systématique et Evolution, UMR CNRS 8079, Université Paris-Sud, F-91405

14 Orsay Cedex, France

15 Centre d'Ecologie et des Sciences de la Conservation (CESCO UMR 7204), Sorbonne

16 Universités, MNHN, CNRS, UPMC, 43 rue Buffon, CP51, 75005, Paris, France

17 irene.castanedagonz@gmail.com 


\section{Abstract (150-250 words)}

Among medium-sized carnivores, red foxes (Vulpes vulpes) and domestic cats (Felis

silvestris catus) are the most abundant species in human-dominated landscapes worldwide. Both are known to be generalist predators that exploit a wide range of prey groups (e.g., mammals, birds, and invertebrates). Identifying red fox and domestic cat predation pressure on shared prey could shed light on their ecological role in shaping wildlife communities in human-dominated landscapes.

Here, we assess the seasonal diet of red foxes and domestic cats in terms of composition, breadth, and overlap. Over two years, we collected their scats across three human-dominated study sites: park ( $n=220$ for foxes and $n=0$ for cats), agricultural land ( $n=159$ for foxes and $n=146$ for cats), and managed forest ( $n=$ 169 for foxes and $n=47$ for cats). We detected similar diet breadth (B) for red foxes and domestic cats $(\mathrm{B}=0.32$ and $\mathrm{B}=0.36$, respectively) as well as strong dietary overlap $(\mathrm{O}=0.83)$ between them. Moreover, the diet composition of both predators varied according to the study sites and seasons. Our results confirm the highly flexible trophic behaviour of these carnivores at the study sites, probably as a consequence of prey availability, and also the simultaneity of their predation over the same prey groups. Future studies should simultaneously monitor predator diet as well as predator and prey abundance in human-dominated landscapes to better understand the predatory impact of red foxes and domestic cats.

\section{Keywords}

39 Diet breadth; diet overlap; domestic cat; red fox; human-dominated landscapes 
41 By 2050, more than half of the world's population will live in urbanized areas (United

42 Nations 2019). Consequently, understanding the functioning of these ecosystems is

43 necessary in order to preserve both biodiversity and human life quality. Human-

44 dominated landscapes share a set of general biotic and abiotic characteristics such as the

45 alteration of species richness (McKinney 2008), the variation of microclimatic

46 conditions (Santamouris et al. 2001), the availability of new resources such as

47 anthropogenic food refuse (Fleming and Bateman 2018), and the lack or reduced

48 number of large carnivores (Crooks 2002; Iossa et al. 2010; Bateman and Fleming

49 2012). In this context, medium-sized carnivores may be "released" in the absence of

50 top-predators (Crooks and Soulé 1999), thus influencing prey populations through top-

51 down processes, as already demonstrated at continental (Ripple et al. 2013) and local

52 scales (Jiménez et al. 2019).

53 Among medium-sized carnivores, the red fox (Vulpes vulpes) is one of the most

54 widespread species (Schipper et al. 2008), while the domestic cat (Felis silvestris catus)

55 is one of the most popular pets worldwide. Out of 18.83 million pets in France, 11.4

56 million are cats. Moreover, the generalist trophic behaviour of red foxes and domestic

57 cats makes them successful species in human-dominated landscapes (Bateman and

58 Fleming 2012). Red fox diets in urban areas are mostly characterized by the presence of

59 anthropogenic food refuse (Harris 1981; Doncaster et al. 1990; Contesse et al. 2004;

60 Hegglin et al. 2007; Meckstroth et al. 2007), while in rural areas, they are more

61 diversified with mammals and birds (Goldyn et al. 2003), mammals, invertebrates, and

62 fruits (Ghoshal et al. 2016), or invertebrates and fruits (Dell'Arte et al. 2005) as the

63 principal food categories. Like red foxes, domestic cats living in urban areas consume

64 not only anthropogenic refuse (Eberhard 1954; Jackson 1951) but also mammals and 
65 birds (Gordon et al. 2010; Tschanz et al. 2011; Thomas et al. 2012). In rural areas,

66 mammals and birds are among the principal prey categories in domestic cat diet (Kays

67 and Dewan 2004; Brickner-Braun et al. 2007; Flux 2007; Morgan et al. 2009; van

68 Heezik et al. 2010). Little is known, however, about how these predators interact with

69 each other or with their shared prey in human-dominated landscapes. In natural or semi-

70 natural habitats, several studies have assessed the influence of fox presence on cat trophic behaviour (Molsher et al. 2017). Moreover, in other natural habitats there exist some degree of trophic competition between these two predators (Catling 1988; Risbey et al. 1999; Glen et al. 2011)

74 Simultaneous monitoring of red fox and domestic cat diets is needed in order to

75 determine their degree of trophic overlap, better assess their concomitant potential

76 predation pressure, and clarify their trophic role in shaping prey communities. To date,

77 however, only one study (Meckstroth et al. 2007) has carried out the simultaneous

78 monitoring of red fox and domestic cat diets in a human-dominated landscape, but none

79 has investigated their degree of diet overlap. In the present study, we firstly aimed to

80 describe red fox and domestic cat diets in three human-dominated landscapes (urban

81 park, agricultural land, and managed forest) across seasons and then estimate their diet

82 breadth and overlap. We hypothesised that both predators consumed a wide range of

83 prey (e.g., large diet breadth) and shared most of them (e.g., high degree of diet

84 overlap), will confirm their generalist trophic behaviour mainly driven by temporal and 85 local specificities.

\section{$87 \quad$ Materials and methods}

$88 \quad$ Study sites 
89 Red fox and domestic cat populations were non-invasively monitored by collecting

90 faecal samples (hereafter, scats) at three suburban study sites (Fig. 1). Sceaux urban

91 park (hereafter, park) $\left(48^{\circ} 46^{\prime} 03.17^{\prime}{ }^{\prime} \mathrm{N}, 2^{\circ} 17^{\prime} 47.48^{\prime \prime} \mathrm{E}\right)$, located $20 \mathrm{~km}$ south of Paris,

92 covers an area of $1.81 \mathrm{~km}^{2}$ and comprises three main habitat types: open areas (lawns

93 and meadows), wooded areas (composed of $16 \%$ Fraxinus sp., 14\% Acer platanoïde,

94 12\% Acer pseudoplatanus, and 9\% Carpinus), and French formal gardens

95 (predominately ornamental species) (Hauts-de-Seine Conseil Général 2015). The

96 agricultural area of Saclay (hereafter, agricultural land) $\left(48^{\circ} 42^{\prime} 32.18^{\prime \prime} \mathrm{N}\right.$,

$\left.972{ }^{\circ} 10^{\prime} 33.00^{\prime \prime} \mathrm{E}\right)$ is located between the north of the Essonne department and the

98 southeast of the Yvelines department. This fertile agricultural land extending over 27

$99 \mathrm{~km}^{2}$ has a long agricultural tradition with the primary crops of colza, wheat, and barley.

100 Currently, this area is facing urbanisation pressure due to the development of a

101 university and laboratory cluster (Spaak 2013). Rambouillet forest (hereafter, forest)

$102\left(48^{\circ} 40^{\prime} 29.84^{\prime \prime} \mathrm{N}, 1^{\circ} 48^{\prime} 27.17^{\prime \prime} \mathrm{E}\right)$, located in the south of the Yvelines department, is

103 one of the largest forests in the Île-de-France region. This wooded area of $200 \mathrm{~km}^{2}$,

104 mainly composed of oaks and coniferous ( $68 \%$ and $25 \%$, respectively), covers a

105 territory of 29 municipalities (Ministère de l'agriculture et de la pêche 2015).

106 Sampling protocol

107 One month prior to the start of predator scat sampling, all study sites were cleaned by

108 removing old scats. Scat sampling was carried out four times per year in the middle of

109 each season (October/autumn; January/winter; April/spring; July/summer) over two

110 consecutive years (2014-2016) for each of the three study sites. Carnivora scats are

111 cylindrical (i.e., sausage-shaped) with sub-division tapped at one of the extremities

112 (Chame 2003). These characteristics may therefore promote scat misidentifications

113 among mammalian carnivores of similar body size (Reid 2015; Morin et al. 2016). Red 
114 fox and domestic cat scats, however, can be differentiated by their morphometry (Bang

115 and Dahlström 1975) and secondarily by their place of deposition, dietary content, and

116 odour. Red fox scats (8-10 cm length and $2 \mathrm{~cm}$ width) are larger than those of domestic

117 cats (6-8 cm length and 1-1.5 cm width) (Chame 2003). Moreover, red fox scats are

118 tubular, long, and twisted with pointed ends, whereas domestic cat scats are smoothed

119 and compacted with well-defined segments and only one tapered extremity (Chame

120 2003). Red foxes usually deposit scats in prominent positions along tracks to signal

121 their presence to other individuals, whereas domestic cats tend to bury theirs (Seton

122 1925, Gibbons 2008). Regarding dietary contents, domestic cat scats strictly reflect their

123 carnivorous diet with the additional presence of grass leaves ingested to aid hair

124 elimination and/or Gramineae seeds indirectly ingested with the grass leaves (Chame

125 2003). Fresh red fox scats present a strong "foxy" smell like middle skunk (Gibbons

126 2008). Scats were collected by walking along the same paths in each study site and

127 season. They were individually geolocalised, stored in separate plastic bags, and frozen

$128\left(-20^{\circ} \mathrm{C}\right)$ until analysis. In this study, we aimed to detect the heterogeneity of predator

129 diet in the main suburban habitats and across seasons. Thus, though informative, within-

130 habitat site replications were not assessed; indeed, this was not possible in the park and

131 agricultural land due to their limited areas. Because of the low number of domestic cat

132 scats collected in the forest and park, we asked volunteer owners to collect the scats of

133 their own vagrant cats during each study period. Four owners from each study site

134 (forest and park) with one to three cats in their house collaborated with us.

135 Due to the small number of red fox and domestic cat scats containing prey remains in

136 some seasons and years, we decided to pool samples by season (i.e., without

137 considering the year). Only seasons with at least 10 scats with prey remains per predator

138 species were included in the following analyses (Table S1). Despite the collaboration of 
139 cat owners, many of the collected scats did not contain any prey remains. As a result,

140 we did not have sufficient numbers of cat scats from the park for all seasons or from the

141 forest in spring to include them in the analyses (Table S1).

142 Laboratory analyses

143 Scats were analysed macroscopically and microscopically. Macroscopic analysis was

144 performed by washing the scats individually under a stream of water in a $2 \mu \mathrm{m}$ sieve.

145 We excluded scats without prey remains (i.e., feathers, hairs, bones, seeds). Prey

146 remains were identified under a binocular to the finest taxonomic level possible using

147 the bone reference collections from the National Museum of Natural History in Paris for

148 mammals and birds, and identification keys for invertebrates and fruits before validating

149 our identifications with specialists of the targeted groups. Indigestible prey remains

150 (e.g., hair, teeth, bones, skin, scales, feathers, exoskeletons, seeds from fleshy fruits)

151 were then classified into 16 main food categories for a more accurate diet comparison:

152 Microtidae (including Myodes glareolus, Microtus agrestis, and Microtus arvalis),

153 Muridae (including Apodemus sylvaticus, Mus musculus, Rattus sp., Rattus norvegicus,

154 and Rattus rattus), Soricidae (including Sorex coronatus, Crocidura leucodon, and

155 Crocidura russula), Leporidae (including Oryctolagus cuniculus and Lepus europaeus),

156 small birds ( size of Passeroidea), large-medium birds ( size of Corvoidea),

157 Coleoptera, Hymenoptera, Dermaptera, Orthoptera, Heteroptera, Lepidoptera,

158 Arachnida, earthworms, small fruits (Prunus cerasus, P. prunus, and Rubus ulmifolius),

159 and large fruits (Malus sp. and Pyrus sp.). We also reported the frequency of nonorganic

160 (e.g., plastic, foil paper) anthropogenic refuse (hereafter, refuse). Coprophagous,

161 recycling, and ticks were excluded from the invertebrate prey. 
162 Microscopic analysis was carried out by subsampling $\sim 2.5 \mathrm{mg}$ of each homogenised

163 predator scat on microscope slides to quantify earthworm consumption based on chaetae

164 counts (Reynolds and Aebischer 1991).

\section{Data analyses}

166 For each scat, we firstly determined the minimum number of consumed prey individuals

167 in each scat (preyмNI) for the main food categories (i.e., excluding refuse). For birds,

168 mammals, and terrestrial arthropods, we counted the number of identical prey fragments

169 contained in each predator scat. For fleshy fruits, preyмNI per predator scat was

170 calculated based on the mean number of seeds (MNS) per fruit collected at the study

171 sites: Rubus ulmifolius $(\mathrm{n}=150, \mathrm{MNS}=52.64)$; Prunus prunus $(\mathrm{n}=39$, $\mathrm{MNS}=1) ; P$.

172 cerasus $(\mathrm{n}=30, \mathrm{MNS}=1)$, Malus $\mathrm{sp} .(\mathrm{n}=73$, MNS $=4.49)$, and Pyrus $\mathrm{sp} .(\mathrm{n}=71$, MNS $=$

173 4.72). For earthworms, we collected the most abundant species (Aporrectodea

174 caliginosa, A. giardi, Allolobophora icterica, and Octolasium cyaneum) from our study

175 sites to measure and calculate their mean fresh weights $(\mathrm{g})$, length $(\mathrm{cm})$, number of

176 segments per individual, and number of chaetae per segment. Prey ${ }_{M N I}$ for earthworms

177 per scat was obtained as follows:

178

$$
\text { (i) } \text { no. chaetae in scat }=\frac{\text { no. chaetae } \times \text { total scat weight }(\text { dry })}{\text { weigth of analysed sample }(0.0025 \mathrm{gr})}
$$

$$
\text { (ii) } \text { no. segments }=\frac{\text { no. chaetae in scat }}{\text { mean no. chaeta per segment }}
$$

$$
\text { (iii) } \text { prey }_{M N I}=\frac{\text { no. of segments }}{\text { no.of segments in one earthworm }}
$$

183 To quantify the ingested prey biomass contained in each scat (prey $y_{\mathrm{IBS}}$ ), we firstly

184 calculated the total ingested biomass (TIB) by multiplying the preyMNI of each prey by

185 its mean mass (MM). The biomass of small mammals $(\mathrm{MM}=57.32 \mathrm{~g})$ and birds $(\mathrm{MM}=$ 
$186 \quad 302.54 \mathrm{~g}$ ) was calculated using weight data extracted from the Amniote trait database

187 (Myhrvold et al. 2015). We estimated invertebrate MM by weighing field-collected

188 individuals from the orders most commonly consumed by the studied predators:

189 Coleoptera $(\mathrm{n}=156, \mathrm{MM}=0.29 \mathrm{~g})$, Hymenoptera $(\mathrm{n}=26, \mathrm{MM}=0.01 \mathrm{~g})$, Dermaptera

$190(n=20, M M=0.03 \mathrm{~g})$, Orthoptera $(n=71, M M=0.10 \mathrm{~g})$, Heteroptera $(n=76, M M=0.02$

$191 \mathrm{~g})$, and Lepidoptera $(\mathrm{n}=92, \mathrm{MM}=0.02 \mathrm{~g})$, as well as the class Arachnida $(\mathrm{n}=87, \mathrm{MM}=$

$1920.01 \mathrm{~g})$. Fruit MM was obtained by collecting and weighing the following fruits from

193 the study sites: Rubus ulmifolius $(\mathrm{n}=150, \mathrm{MM}=2.19 \mathrm{~g})$, Prunus prunus $(\mathrm{n}=39, \mathrm{MM}=$

$19415.09 \mathrm{~g})$, P. cerasus $(\mathrm{n}=30, \mathrm{MM}=3.70 \mathrm{~g})$, Malus $\mathrm{sp} .(\mathrm{n}=73$, mean $\mathrm{MM}=90.01 \mathrm{~g})$, and

195 Pyrus sp. (n=71, MM=98.55 g). Since red foxes and domestic cats are known to ingest

196 large body mass prey (e.g., Leporidae, large birds) only partially (Artois 1989; Bonnaud

197 et al. 2007), we estimated the ingested proportion of lagomorphs and large-medium

198 birds by calculating the maximum food intake per scat of each predator. To do so, we

199 selected red fox $(n=75)$ and domestic cat $(n=53)$ scats containing only small mammals

200 (i.e., prey entirely ingested) and multiplied their preyMNI by their MM to obtain a

201 maximum ingested biomass (MIB in $g$ of fresh biomass) for each predator scat. MIB

202 was $244.09 \mathrm{~g}$ and $232.40 \mathrm{~g}$ for red fox and domestic cat, respectively. We then

203 calculated the ingested biomass of each prey category per scat (prey IBS ) by using one of

204 the two following formulas. If the TIB did not exceed the MIB, we applied the formula:

(iv) prey $_{I B S}=$ small prey $_{i} M M \times$ small prey $_{i} M N I$

208 If the TIB exceeded the MIB due to the consumption of large prey like lagomorph and

209 large-medium birds, for instance, we applied the following formula: 


$$
\text { (v) } \text { prey }_{I B S}=\frac{M I B-\sum_{i}^{n}\left(\text { small prey }_{i} M M \times \text { small prey }_{i} M N I\right)}{R I B_{j}}
$$

Where $\mathrm{RIB}_{\mathrm{j}}$ is the relative ingested biomass of each large prey calculated as follows:

$$
(v i) R I B_{j}=\frac{\left(\text { large prey }_{j} \text { biomass } \times \text { large prey }_{j} \text { number }\right)}{\sum_{1}^{n}\left(\text { large prey } \text { lamass }_{j} \times \text { large prey }_{j} \text { number }\right)}
$$

\section{Effects of study sites and seasons on predator diet}

218 We chose multivariate generalised linear models (hereafter, GLMs) to detect factors

219 (i.e., predator, study site, and season) that could affect diet composition, because our 220 dietary data had a strong mean-variance relationship that was taken into account in these models (Wang et al. 2016). Firstly, we fitted one global GLM using the following

222 formula: diet $\sim$ predator + study site * season. Secondly, we fitted one GLM for each

223 predator species using the following formula: predator diet $\sim$ study site ${ }^{*}$ season. We

224 then ran univariate analysis of variance for each prey category and adjusted the p-value

225 for multiple testing with a step-down resampling procedure (Wang et al. 2016). We

226 used 999 bootstrap iterations to sample multivariate GLM residuals. Models were fitted

227 with the manyglm function from the mvabund package (Wang et al. 2016). Although we

228 only discuss the results from the models with prey ${ }_{\text {IBS }}$ as the response variable, as it is

229 the best approximation of the true diet of predators (Klare et al. 2011), we also included

230 the results from the global model for each of the two diet descriptors (preyMNI and

231 preyмNI) as response variables (Table S2) and from the model using preyMNI as the

232 response variable (Table S3).

233 Predator diet breadths and overlaps 
234 We used preymNI to calculate the degree of trophic specialisation for each studied

235 predator by estimating their diet breadth (B) and degree of diet overlap (O) using the

236 nichevar and nicheoverlap functions from the indicspecies package, respectively

237 (Caceres and Legendre 2009). Diet breadth ranges from 0 to 1, with values close to 0 for

238 specialised populations and values close to 1 for generalists. Diet overlap ranges from 0

239 to 1 , with values close to 0 for low diet overlap between predator populations and

240 values close to 1 for high diet overlap.

241 We visually assessed dietary overlap between predators, study sites, and seasons using

242 nonmetric multidimensional scaling (NMDS) plots. This multivariate method is based

243 on a triangular resemblance matrix of Bray-Curtis similarities among all pairs of

244 samples. We used the metaMDS function from the vegan package (Oksanen et al. 2018)

245 to produce NMDS plots. All statistical analyses were carried out using R Studio version

246 1.1.463. (R Core Team 2019).

\section{$248 \quad$ Results}

249 In total, we collected 1,073 scats, but 332 did not contain any wild prey remains (i.e., 250 only highly digestible organic matter like industrial food and/or refuse), with $55 \%$ of

251 them belonging to red foxes (park: $n=94$, agricultural land: $n=24$, managed forest: $n=$

25265 ) and $45 \%$ to domestic cats (park: $n=85$, agricultural land: $n=21$, managed forest: $n$

$253=43)($ Table S1). From the remaining 741 scats containing prey remains, $74 \%$ belonged

254 to red foxes (park: $n=220$, agricultural land: $n=159$, managed forest: $n=169$ ) and

$25526 \%$ to domestic cats (park: $n=0$, agricultural land: $n=146$, managed forest: $n=47$ )

256 (Table S1). Out of these 741 scats, 41 scats contained prey remains that were not

257 attributable to the 16 main prey groups defined above (e.g., scats containing

258 unidentifiable parts of invertebrates, seeds, feathers, or hairs). This resulted in the 
259 inclusion of 700 scats in prey ${ }_{\mathrm{IBS}}$ and prey ${ }_{\mathrm{MNI}}$ models, corresponding to 699 degrees of

260 freedom in general models and 521 and 177 degrees of freedom in red fox $(n=522)$ and

261 domestic cat $(n=178)$ models, respectively.

262 We identified a total of 6,742 prey items. Based on prey ${ }_{\mathrm{IBS}}$, red fox diet was mainly

263 composed of Rodentia (37\%) and large-medium birds (28\%), and domestic cat diet of

264 Leporidae (41\%) and large-medium birds (27\%) (Table 1). Based on the preymNI, red

265 fox diet was mainly composed of earthworms (53\%), and domestic cat diet of

266 earthworms (40\%) and Microtidae (21\%) (Table 1).

267 The composition of both predators' diets (prey ${ }_{\mathrm{IBS}}$ ) was influenced by predator species,

268 study sites, seasons, and the interaction between study sites and seasons (Table S2a).

269 Predator species affected diet prey

270 earthworms, and small fruits. Study site affected both predators' consumption of

271 Leporidae, Microtidae, Muridae, Soricidae, large-medium birds, Coleoptera, and

272 earthworms. Seasons influenced both predators' diets in terms of Coleoptera,

273 earthworms, and small fruits. The interaction between study site and season also

274 affected both predators' diets in terms of Leporidae, large-medium birds, Coleoptera,

275 and small fruits (Table S2a).

276 Red fox diet

277 The composition of red fox diet (prey ${ }_{\mathrm{IBS}}$ ) was influenced by study sites, seasons, and the

278 interaction between study sites and seasons (Table 2a). Study site affected red fox

279 prey ${ }_{\text {IBS }}$ in terms of Microtidae, Muridae, large-medium birds, Coleoptera, earthworms,

280 and small fruits. Seasons influenced red fox consumption of Coleoptera, earthworms,

281 and small fruits. The interaction between study site and season also affected red fox

282 prey ${ }_{\text {IBS }}$ in terms of large-medium birds, Coleoptera, and small fruits (Table 2a). 
283 Based on the ingested prey biomass (prey

284 composed of large-medium birds (66\%), especially in autumn (73\%), spring, (99\%),

285 and summer (60\%) (Table 1). In agricultural land, red fox diet principally comprised

286 large-medium birds (35\%), especially in autumn (50\%) and summer (37\%), followed by

287 Leporidae (28\%), mainly in autumn (37\%), winter (20\%), and summer (30\%) (Table 1).

288 In the forest, red fox diet was mainly composed of Leporidae (36\%), especially in

289 autumn (98\%) and spring (98\%), followed by Muridae (29\%), principally in winter

$290 \quad(53 \%)$ (Table 1).

291 Based on the minimum number of ingested individuals (prey ${ }_{M N I}$ ), in the park, red fox

292 diet was mainly composed of earthworms (61\%), particularly in autumn (90\%), winter

293 (77\%), and spring (87\%). In agricultural land, red fox diet principally comprised small

294 fruits (38\%), especially in summer (55\%), followed by earthworms (33\%), mostly in

295 autumn (61\%), winter (36\%), and spring (64\%). In the forest, earthworms were the

296 principal food category in red fox diets (56\%), especially in winter (79\%) and spring

297 (64\%) (Table 1).

298 Domestic cat diet

299 Domestic cat diet composition was influenced by the seasons as well as the interaction

300 between study site and season. In particular, seasons had an influence on domestic cat

301 preyIBS in terms of earthworm biomass (Table 2b).

302 Based on the ingested prey biomass (prey $y_{\mathrm{IBS}}$ ), in agricultural land, domestic cat diet was

303 mainly composed of Leporidae (57\%), especially in autumn (67\%), winter (52\%), and

304 spring (77\%) (Table 1). In the forest, domestic cat diet principally comprised Muridae

305 (43\%), particularly in summer (70\%), followed by large-medium birds $(18 \%)$,

306 especially in summer (64\%) (Table 1). 
307 Based on the minimum number of ingested individuals (prey ${ }_{\mathrm{MNI}}$ ), in agricultural land,

308 domestic cat diet was mainly composed of earthworms (48\%), particularly in autumn

309 (60\%), winter (64\%), and spring (34\%), followed by Microtidae (20\%), especially in

310 summer (34\%) (Table 1). In the forest, domestic cat diet mainly comprised earthworms

311 (22\%), particularly in autumn (65\%) and winter (47\%), followed by Microtidae (22\%),

312 especially in summer (52\%) (Table 1).

313 Diet breadth and overlap

314 According to the results of the diet breadth index, both predators exhibited a narrow diet

315 breadth at all study sites and across seasons $(\mathrm{B}<0.40)$, with the diet breadth of each

316 predator being similar (red fox: $\mathrm{B}=0.32,95 \% \mathrm{CI}[0.29,0.34]$; domestic cat: $\mathrm{B}=0.36$,

$31795 \%$ CI $[0.31,0.39])$ across study sites and seasons (Fig. 2).

318 Interestingly, in agricultural land, we found a high degree of diet overlap between red

319 fox and domestic cat populations across all seasons $(\mathrm{O}>0.75)$ except summer $(\mathrm{O}=$

$320 \quad 0.33,95 \%$ CI $[0.20,0.56])$ (Table S4). During this season, dissimilarity between red fox

321 and domestic cat diet (i.e., points located far from each other with little or no overlap)

322 was higher compared to the other seasons (Fig. 3a). By contrast, we detected higher

323 variations in the diet overlap between red fox and domestic cat populations in the forest

324 compared to agricultural land, with the highest value found in winter $(\mathrm{O}=0.9295 \% \mathrm{CI}$

$325[0.05,0.99])$ and the lowest in summer $(\mathrm{O}=0.2595 \%$ CI $[0.04,0.60])$ (Table S4). In

326 winter, red fox and domestic cat diet showed the highest similarity (i.e., most points are

327 spatially close to each other or overlapping), while the lowest diet similarity was

328 observed in summer (Fig. 3b). Due to the limited number of collected cat scats in some

329 habitats and seasons, we did not calculate the diet overlap between red fox and domestic

330 cat populations in the forest in spring or in the park for all seasons. 


\section{Discussion}

333 Results obtained in this study were only based on the analysis of scats containing wild 334 prey remains (i.e., $75 \%$ and $56 \%$ of red fox and domestic cat scats, respectively). The

335 high proportion of domestic cat scats without any wild prey remains (i.e., containing 336 only highly digestible organic matter like industrial food and/or refuse) is partly due to 337 the high percentage $(70 \%)$ of scats that were provided by cat owners, meaning that 338 domestic cats were primarily sustained by human-mediated food while having the 339 opportunity to wander and feed on wild prey. Even if the percentage of red fox scats 340 containing only refuse and/or industrial food is lower than that of domestic cat scats, 341 this indicates that red foxes, particularly in suburban areas, are able to feed on human-

342 mediated food. This feeding habit may provide them with some adaptive and/or survival 343 advantages.

\section{Red fox and domestic cat diets}

345 The trophic index based on ingested prey biomass (preyIBs) revealed that large-medium

346 birds and mammals were the prey categories most contributing to red fox and domestic

347 cat food bolus. Invariably, red fox and domestic cat diets were dominated by large prey

348 (i.e., large-medium birds and Leporidae) and/or medium-sized prey (Muridae) across all

349 study sites and seasons. This result suggests that the survival of both predators mainly

350 depends on prey with a large biomass (e.g., medium-large birds, Leporidae), probably

351 because one killed individual represents a large source of metabolizable energy.

352 The trophic index based on the minimum number of ingested individuals (prey

353 revealed that earthworms were the most abundantly consumed prey in red fox diet. This

354 result is in good agreement with other studies once refuse is removed from red fox diet

355 (MacDonald 1980; Harris 1981; Doncaster et al. 1990; Reynolds and Aebischer 1991;

356 Saunders et al. 1993; Soulsbury et al. 2008). In domestic cat diet, earthworms along 
with Microtidae were the most abundantly consumed prey. While the presence of

358 chaetae in predator scats may be increased by phenomena such as soil contamination

359 and secondary predation (i.e., chaetae would have persisted after two digestions),

360 potentially leading to a slight overestimation of earthworm consumption, the high

361 number of consumed earthworms stresses the importance of this prey type for both red

362 foxes and domestic cats, as it may supply these predators with their protein

363 requirements within human-dominated landscapes. Even if striking, the consumption of

364 earthworms (protein-rich prey) by domestic cats is probably opportunistic and focussed

365 on anecic and/or epigeic earthworms (Lee 1985), which are readily available and easy to

366 catch in agricultural and forest soils. This interesting result should be confirmed (i.e.,

367 earthworm species identification) in future studies using metabarcoding approaches, for

368 example (Bienert et al. 2012; Boyer et al. 2013; Pansu et al. 2015). In general, the

369 macro- and microscopic diet analyses of predator diets would benefit from

370 metabarcoding approaches to verify prey identification, detect and identify digested

371 soft-bodied prey (e.g., insect larvae, egg content), and confirm predator scat

372 identification (Pompanon et al. 2012; Galan et al. 2018).

373 Specific spatiotemporal diet patterns for red foxes and domestic cats

374 Red fox populations showed study site specificities in terms of the proportion of

375 ingested biomass for certain prey categories (Microtidae, Muridae, large-medium birds,

376 Coleoptera, earthworms, and small fruits) as well as seasonal dietary shifts for some of

377 these resources (Coleoptera, earthworms, and small fruits) (Tables 1 and 2a).

378 These results are in good agreement with and support the generalist and opportunistic

379 trophic behaviour of red foxes (Sillero et al. 2004). Thanks to this trophic behaviour, red

380 foxes could adapt their diet in contrasting human-dominated landscapes according to the 
381 abundance and availability of associated prey communities and fruit resources (e.g.,

382 emergence of Coleoptera, fructification of fleshy fruits) (Díaz-Ruiz et al. 2013).

383 In contrast to red fox diet, domestic cat diet (in terms of ingested prey biomass) was

384 relatively homogeneous across study sites and mainly focussed on mammals (Leporidae

385 and Muridae; Gillies and Fitzgerald 2005 (New Zealand); Kays and Dewan 2004 (US);

386 Krauze-Gryz et al. 2012 (Europe)) and secondarily on large-medium birds, with only

387 the proportion of ingested earthworm biomass changing seasonally (Tables 1 and $2 b$ ).

388 This suggests that cats are highly adaptable and efficient hunters, which allows them to

389 survive and reproduce without regard to the type of habitat, thus confirming the

390 opportunistic but strictly carnivore trophic behaviour of domestic cats (Bradshaw et al.

391 1996; Medina et al. 2011). By consequence, the increased number of vagrant domestic

392 cats due to the higher human population density can lead to negative effects on bird,

393 mammal, and reptile population dynamics in many different types of habitats (Woods et

394 al. 2003; Dauphiné and Cooper 2009; Blancher 2013; Loss et al. 2013; Doherty et al.

395 2015). As the opportunistic behaviour of these predators likely depends on resource

396 abundance and availability, which are rarely monitored and quantified, this should be

397 investigated in future studies to detect potential patterns of prey preferences.

398 At all the study sites, both red foxes and domestic cats abundantly consumed

399 earthworms (in preyMNI) in autumn, winter, and spring, probably due to the scarcity of

400 other prey categories during these seasons of relatively low productivity. The use of this

401 alternative high-protein prey may allow red foxes and domestic cats to maintain stable

402 populations all year round within degraded human-dominated landscapes. Interestingly,

403 in agricultural land, domestic cats turned to the consumption of Microtus agrestis

404 individuals as observed in other rural areas in Europe (Krauze-Gryz et al. 2012), while

405 red foxes shifted their diet to temporarily abundant small fruits that are rich in 
ulmifolius) (Table 1). Red fox consumption of fruits has already been described in other studies in Europe (Contesse et al. 2004) and Asia (Dell'Arte et al. 2005; Ghoshal et al. 2016). In addition to being an alternative source of nutrient for foxes, these fruits contained seeds that can be efficiently dispersed (Herrera 1989; Matías et al. 2010),

411 leading to the conservation of the vegetation structure of these habitats. Last but not 412 least, the consumption of voles by domestic cats in summer likely corresponds to a peak

413 abundance of this prey, which supports the opportunistic trophic behaviour of cats. As

414 domestic cats are one of the major predators of voles (Lin and Batzli 1995), they could

415 modify the cyclicity of the prey population dynamics (Hansson 1988) and indirectly

416 affect the trophic behaviour of other predators sharing this prey such as red foxes.

417 Diet breadth and overlap

418 Although we showed that red foxes and domestic cats are able to exploit a wide

419 spectrum of trophic resources (i.e., mammals, birds, invertebrates, and fruits) within

420 human-dominated landscapes, these predators exhibit quite a narrow diet breadth

421 similarly to those described by other authors in natural habitats (Drygala et al. 2014;

422 Vlasseva et al. 2017; Széles et al. 2018). This result confirms that these predators hunt 423 targeted prey groups with a focus on large birds and mammals.

424 Because foxes and cats had similarly varied diets across habitat types and seasons, we 425 have confidence in the main result of a high dietary overlap despite the lack of within426 habitat site replication.

427 These are the first results regarding the degree of diet overlap between red foxes and 428 domestic cats within human-dominated landscapes, which are in good agreement with 429 those found in natural habitats (Paltridge 2002; Woinarski et al. 2017). In our study, in 430 summer, red fox and domestic cat diets only marginally overlapped, suggesting that they 
431 can hunt a wider prey spectrum to reduce their degree of trophic overlap through niche

432 partitioning. On the contrary, diet overlaps between red foxes and domestic cats were

433 particularly high during the less productive seasons (i.e., autumn, winter, and spring)

434 when they have to share scarcer main and alternative prey (i.e., mammals, birds, and

435 earthworms). This indicates that competition between red foxes and domestic cats may

436 occur, particularly if these predators are in high abundance in city centres (Š́lek et al.

437 2015; Flockhart et al. 2016) and probably more broadly in human-dominated areas.

438 However, competition for food between species is eased by their generalist behaviour.

439 In addition, these high seasonal diet overlaps between red foxes and domestic cats may

440 exacerbate their predation pressure over shared prey populations and can lead to

441 potential negative effects on shared prey population dynamics. To quantify predation

442 impacts on prey population dynamics, future studies should simultaneously monitor

443 predator diets as well as prey and predator availabilities through space and time.

445 Author's contributions

446 IC collected and analysed the data and led the writing of the manuscript. DZL

447 contributed to performing the diet descriptors. EB conceived the ideas and designed the

448 methodology. All authors contributed to the writing and gave their final approval for

449 publication.

451 Acknowledgements

452 This work was supported by a Region Ile-de-France PhD scholarship for IC and by the

453 Chair "Modélisation Mathématique et Biodiversité" of VEOLIA-Ecole Polytechnique-

454 MnHn-FX and the Labex BASC through flagship projects for DZL. Raquel Monclús 
455 kindly reviewed this manuscript. We also thank all the students who participated in the 456 field and laboratory work. 
458 Bang P, Dahlström P (1975) Huellas y Señales de los Animales de Europa, Omega, $459 \quad$ Barcelona.

460 Bateman PW, Fleming PA (2012) Big city life: Carnivores in urban environments. J Zool 287:1-23. doi: 10.1111/j.1469-7998.2011.00887.x

Bienert F, De Danieli S, Miquel C, et al (2012) Tracking earthworm communities from 463 soil DNA. Mol Ecol 21:2017-2030. doi: 10.1111/j.1365-294X.2011.05407.x

Blancher P (2013) Estimated number of birds killed by house cats (Felis catus) in Canada. Avian Conserv Ecol 8:3. doi: 10.5751/ACE-00557-080203

Caceres M De, Legendre P (2009) Associations between species and groups of sites: Israeli wildlife. Isr J Ecol Evol 53:129-142. doi: 10.1560/IJEE.53.2.129 indices and statistical inference. Ecology 90:3566-3574. doi: 10.1890/08-1823.1

Catling PC (1988) Similarities and contrasts in the diets of foxes, Vulpes vulpes, and Cats, Felis catus, relative to fluctuating prey populations and drought. Aust Wildl 
Contesse P, Hegglin D, Gloor S, et al (2004) The diet of urban foxes (Vulpes vulpes) and the availability of anthropogenic food in the city of Zurich, Switzerland. Mamm Biol 69:81-95. doi: 10.1078/1616-5047-00123

Crooks K, Soulé M (1999) Mesopredator release and avifaunal extinctions in a fragmented system. Nature 400:563-566. doi: 10.1038/23028

Crooks KR (2002) Relative Sensitivites of Mammalian Carnivores to Habitat Fragmentation. Conserv Biol 16:488-502. doi: 10.1046/j.1523-1739.2002.00386.x

Dauphiné N, Cooper RJ (2009) Impacts of free-ranging domestic cats (Felis catus) on birds in the United States: a review of recent research with conservation and management recommendations. Proc Fourth Int Partners Flight Conf Tundra to Trop 205-219

Dell'Arte GL, Leonardi G, Dell'Arte GL, et al (2005) Effects of habitat composition on

Doherty TS, Davis RA, van Etten EJB, et al (2015) A continental-scale analysis of feral cat diet in Australia. J Biogeogr 42:964-975. doi: 10.1111/jbi.12469

Doncaster CP, Dickman CR, Macdonald DW (1990) Feeding ecology of red foxes in the city of Oxford, England. J Mammal 71:188-194. doi: 10.2307/1382166 
507 Fleming PA, Bateman PW (2018) Novel predation opportunities in anthropogenic $508 \quad$ landscapes. Anim Behav 138:145-155. doi: 10.1016/j.anbehav.2018.02.011

509 Flockhart DTT, Norris DR, Coe JB (2016) Predicting free-roaming cat population 510 densities in urban areas. Anim Conserv 19:472-483. doi: 10.1111/acv.12264

511 Flux JEC (2007) Seventeen years of predation by one suburban cat in New Zealand.

$512 \quad$ New Zeal J Zool 34:289-296. doi: 10.1080/03014220709510087

513 Galan M, Pons J-B, Tournayre O, et al (2018) Metabarcoding for the parallel

514 identification of several hundred predators and their preys: application to bat

515 species diet analysis. Mol Ecol Resour 18:474-489. doi:

$516 \quad 10.1017 / \mathrm{CBO} 9781107415324.004$

517 Ghoshal A, Bhatnagar YV, Mishra C, Suryawanshi K (2016) Response of the red fox to 518 expansion of human habitation in the Trans-Himalayan mountains. Eur J Wildl Res 62:131-136. doi: 10.1007/s10344-015-0967-8

520 Glen AS, Pennay M, Dickman CR, et al (2011) Diets of sympatric native and

521 introduced carnivores in the Barrington Tops, eastern Australia. Austral Ecol 36:290-296. doi: 10.1111/j.1442-9993.2010.02149.x

Goldyn B, Hromada M, Surmacki A, Tryjanowski P (2003) Habitat use and diet of red fox Vulpes vulpes in an agricultural landscape in Poland. Z jagdwiss 49:191-200

525 Gordon JK, Matthaei C, Van Heezik Y (2010) Belled collars reduce catch of domestic cats in New Zealand by half. Wildl Res 37:372-378. doi: 10.1071/WR09127

Hansson L (1988) The domestic cat as a possible modifier of vole dynamics. Mammalia 52:159-164. doi: 10.1515/mamm.1988.52.2.159

Harris S (1981) The food of suburban foxes (Vulpes vulpes), with species reference to London. Mamm Rev 11:151-168

531 Hegglin D, Bontadina F, Contesse P, et al (2007) Plasticity of predation behaviour as a 
putative driving force for parasite life-cycle dynamics: The case of urban foxes and

533 Echinococcus multilocularis tapeworm. Funct Ecol 21:552-560. doi: $10.1111 / j .1365-2435.2007 .01257 . x$

Herrera CM (1989) Frugivory and Seed Dispersal by Carnivorous Mammals, and Associated Fruit Characteristics, in Undisturbed Mediterranean Habitats. Oikos 55:250. doi: $10.2307 / 3565429$

Jackson WB (1951) Food habits of Baltimore, Maryland, cats in relation to rat populations. J Mammal 82:458-461

540 Jiménez J, Nuñez-Arjona JC, Mougeot F, et al (2019) Restoring apex predators can

541 reduce mesopredator abundances. Biol Conserv 238:108234. doi: 10.1016/j.biocon.2019.108234

Kays RW, Dewan AA (2004) Ecological impact of inside/outside house cats around a suburban nature preserve. Anim Conserv 7:1-11. doi: $10.1017 / \mathrm{S} 1367943004001489$

Klare U, Kamler HF, MacDonald DW (2011) A comparison and critique of different scat-analysis. Mamm Rev 41:294-312. doi: 10.1111/j.1365-2907.2011.00183.x

Krauze-Gryz D, Gryz J, Goszczyński J (2012) Predation by domestic cats in rural areas of central Poland: An assessment based on two methods. J Zool 288:260-266. doi:

Lin YK, Batzli GO (1995) Predation on Voles: An Experimental Approach. J Mammal $76: 1003-1012$

Loss SR, Will T, Marra PP (2013) The impact of free-ranging domestic cats on wildlife of the United States. Nat Commun 4:1396. doi: 10.1038/ncomms2380 
Matías L, Zamora R, Mendoza I, Hódar JA (2010) Seed Dispersal Patterns by Large Frugivorous Mammals in a Degraded Mosaic Landscape. Restor Ecol 18:619-627. doi: 10.1111/j.1526-100X.2008.00475.x

McKinney ML (2008) Effects of urbanization on species richness: A review of plants and animals. Urban Ecosyst 11:161-176. doi: 10.1007/s11252-007-0045-4

Meckstroth AM, Miles AK, Chandra S (2007) Diets of Introduced Predators Using Stable Isotopes and Stomach Contents. J Wildl Manage 71:2387. doi: $10.2193 / 2005-527$

Medina FM, Bonnaud E, Vidal E, et al (2011) A global review of the impacts of

Myhrvold NP, Baldridge E, Chan B, et al (2015) An amniote life-history database to

Morgan SA., Hansen CM, Ross JG, et al (2009) Urban cat (Felis catus) movement and

predation activity associated with a wetland reserve in New Zealand. Wildl Res

Molsher R, Newsome AE, Newsome TM, Dickman CR (2017) Mesopredator management: Effects of red fox control on the abundance, diet and use of space by feral cats. PLoS One 12:1-15. doi: 10.1371/journal.pone.0168460 36:574-580. doi: 10.1071/WR09023

perform comparative analyses with birds, mammals, and reptiles. Ecology 96:3109-000. doi: 10.1890/15-0846R.1

Oksanen AJ, Blanchet FG, Kindt R, et al (2018) Package ‘ vegan’

Paltridge R (2002) The diets of cats, foxes and dingoes in relation to prey availability in

581 Pansu J, De Danieli S, Puissant J, et al (2015) Landscape-scale distribution patterns of 
earthworms inferred from soil DNA. Soil Biol Biochem 83:100-105. doi:

Pompanon F, Deagle BE, Symondson WOC, et al (2012) Who is eating what: Diet assessment using next generation sequencing. Mol Ecol 21:1931-1950. doi:

$$
\text { 10.1111/j.1365-294X.2011.05403.x }
$$

587

Reynolds JC, Aebischer NJ (1991a) Comparison and Quantification of Carnivore Diet by Fecal Analysis - A Critique, with Recommendations, Based on A Study of the Fox Vulpes-Vulpes. Mamm Rev 21:97-122. doi: 10.1111/j.13652907.1991.tb00113.x

Reynolds JC, Aebischer NJ (1991b) Comparison and quantification of carnivore diet by faecal analysis: a critique, with recommendations, based on a study of the Fox VUlpes vulpes. Mamm Rev 21:97-122

Ripple WJ, Wirsing AJ, Wilmers CC, Letnic M (2013) Widespread mesopredator effects after wolf extirpation. Biol Conserv 160:70-79. doi:

$$
\text { 10.1016/j.biocon.2012.12.033 }
$$

Risbey DA, Calver MC, Short J (1999) The impact of cats and foxes on the small

600 Šálek M, Drahníková L, Tkadlec E (2015) Changes in home range sizes and population 601 densities of carnivore species along the natural to urban habitat gradient. Mamm $602 \quad \operatorname{Rev} 45: 1-14$. doi: 10.1111/mam.12027

603 Santamouris M, Papanikolaou N, Livada I, et al (2001) On the impact of urban climate 604 on the energy consumption of buildings. Sol Energy 70:201-216. doi: $10.1016 / \mathrm{S} 0038-092 \mathrm{X}(00) 00095-5$

606 Saunders G, White PCL, Harris S, Rayner JMV (1993) Urban foxes (Vulpes vulpes): 
food acquisition, time and energy budgeting of a generalized predator. Symp zool

608 Soc L 65:215-234

609

Schipper J, Chanson JS, Chiozza F, et al (2008) The status of the world's land and

610 marine mammals: diversity, threat, and knowledge. Science (80- ) 322:225-230. doi: 10.1126/science.1165115

612 Seton ET (1925) On the Study of Scatology. J Mammal 36:47-49. doi: 10.1644/870.1.Key

614 Sillero C, Macdonald D, Hoffmann M (2004) Canids : Foxes, Wolves, Jackals and 615 Dogs. Status asurvey and Conservation Action Plan

616 Soulsbury CD, Iossa G, Baker PJ, Harris S (2008) Environmental variation at the onset 617 of independent foraging affects full-grown body mass in the red fox. 2411-2418. $618 \quad$ doi: $10.1098 / \mathrm{rspb} .2008 .0705$

619 Széles GL, Purger JJ, Molnár T, Lanszki J (2018) Comparative analysis of the diet of 620 feral and house cats and wildcat in Europe. Mammal Res 63:43-53. doi: $10.1007 / \mathrm{s} 13364-017-0341-1$

622 Thomas RL, Fellowes MDE, Baker PJ (2012) Spatio-Temporal Variation in Predation 623 by Urban Domestic Cats ( Felis catus ) and the Acceptability of Possible Management Actions in the UK. 7:20-23. doi: 10.1371/journal.pone.0049369

625 Tschanz B, Hegglin D, Gloor S, Bontadina F (2011) Hunters and non-hunters: Skewed 626 predation rate by domestic cats in a rural village. Eur J Wildl Res 57:597-602. doi:

628 United Naions, Department of Economic and Social Affairs PD (2019) World 629 Urbanization Prospects: The 2018 Revision (ST/ESA/SER.A/420)

630 van Heezik Y, Smyth A, Adams A, Gordon J (2010) Do domestic cats impose an 631 unsustainable harvest on urban bird populations? Biol Conserv 143:121-130. doi: 
633 Vlasseva A, Chassovnikarova T, Atanassov N (2017) Autumn-winter diet and food 634 niche overlap between red fox (Vulpes vulpes L., 1758) and golden Jackal (Canis 635 aureus L., 1758) in two Regions in Bulgaria. Acta Zool Bulg 69:217-220

636 Wang Y, Naumann U, Eddelbuettel D, et al (2016) Statistical methods for analysing 637 multivariate abundance data. Package 'mvabund'. R Proj. Stat. Comput. Vienna, $638 \quad$ Austria

639 Woinarski JCZ, South SL, Drummond P, et al (2017) The diet of the feral cat (Felis 640 catus), red fox (Vulpes vulpes) and dog (Canis familiaris) over a three-year period 641 at Witchelina Reserve, in arid South Australia. Aust Mammal 40:204-213. doi: 10.1071/AM17033

643 Woods M, Mcdonald RA, Phen STE, et al (2003) Predation of wildlife by domestic cats 644 Felis catus in Great Britain. Mamm Rev 33:174-188. doi: DOI 10.1046/j.1365$645 \quad 2907.2003 .00017 . x$ 